\section{Internuclear Ophthalmoplegia}

Douglas I. Katz

Department of Neurology, Boston University

School of Medicine, Braintree, MA, USA

\section{Definition}

Internuclear ophthalmoplegia (INO) is an inability to produce conjugate adduction of one eye while the other eye is abducting during lateral gaze. INOs are caused by lesions in the medial longitudinal fasciculus (MLF) that interrupt connections from the cranial nerve VI (abducens) nucleus to the opposite cranial nerve III (oculomotor) nucleus, necessary for yoked, lateral movements of the eyes. The medial rectus ipsilateral to the MLF lesion does not adequately adduct the eye while lateral rectus of the opposite, abducting eye is stimulated to contract. Often there is a lateral beating nystagmus of the abducting eye associated with the abnormal movement of the adducting eye.

\section{Cross-References}

Diplopia

- Lateral Gaze Palsy

$\checkmark$ Oculomotor Nerve

\section{References and Readings}

Leigh, R. J., \& Zee, D. S. (2006). The neurology of eye movements (4th ed.). New York: Oxford University Press. 